Open Access

\title{
The role of EFL learners' demotivation, perceptions of classroom activities, and mastery goal in predicting their language achievement and burnout
}

\author{
Safoura Jahedizadeh ${ }^{1}$, Afsaneh Ghanizadeh ${ }^{1 *}$ and Behzad Ghonsooly ${ }^{2}$
}

* Correspondence:

a.ghanizadeh@imamreza.ac.ir

${ }^{1}$ Imam Reza International University, Mashhad, Iran

Full list of author information is available at the end of the article

\begin{abstract}
The present study aims at delving into English as foreign language students' demotivation, burnout, mastery goal orientation, and perceptions of classroom activities. This is accomplished by building a causal structural model through which the associations among the constructs are estimated. The Persian version of the 'de-motivation scale' designed by Sakai and Kichuki (System 37:57-69, 2009) is used to assess demotivation. It measures six constructs: teachers, characteristics of classes, experiences of failure, class environment, class materials, and lack of interest. To gauge burnout, student version of 'Maslach Burnout Inventory' (Schaufeli et al., Psychology, 33(5):464-481, 2002) is employed. It measures three dimensions of burnout, namely, emotional exhaustion, cynicism, and academic inefficacy. The Persian version of the 'Students Perceptions of Classroom Activities' scale designed by Gentry and Gable (My class activities: A survey instrument to assess students' perceptions of interest, challenge, choice, and enjoyment in their classrooms, 2001) is utilized in determining student perceptions of their classes. The scale assesses four perceptions: interest, challenge, choice, and joy. Students' goal orientation is measured by the translated version of 'Achievement Goal Orientation Inventory' designed by Midgley et al. (Contemporary Educational Psychology, 23 (2):113-31, 1998). The results display a good overall fit of the proposed model with the empirical data. In particular, demotivators positively and significantly predict student burnout and the two internal demotivators namely, 'lack of interest' and 'experiences of failure' negatively and significantly impact on student mastery goal orientation. The results also indicate that student burnout negatively and significantly predict student mastery goal orientation and positive perceptions of classroom activities. Student perceptions of interest and joy, on the other hand, positively and significantly play an important role in mastery goal orientation. Student perceptions and mastery goal orientation have positive effects on student achievement.
\end{abstract}

Keywords: Demotivation, Perceptions of classroom activities, Mastery goal, Burnout, Language achievement, SEM 


\section{Introduction}

As a theoretical construct, the concept of motivation is used to explain a process which initiates, guides, and maintains goal oriented treatments. Dörnyei (2001) defined motivation as a highly complex and multifaceted issue shaping one of the most crucial human characteristics. Dörnyei and Ottó (1998) referred to motivation as a changing arousal in an individual that instigates, terminates, and evaluates the cognitive processes in which primary desires and wishes can be prioritized and acted out (successfully or unsuccessfully). The flip side of motivation known as demotivation has recently attracted the attention of educationalists (e.g., Ghanizadeh \& Jahedizadeh, 2015a, d; Jahedizadeh \& Ghanizadeh, 2015; Zhang, 2007; Molavi \& Biria, 2013). According to Dörnyei (2001), de-motivation reduces the motivational basis of a behavioural intention or an on-going action. In the domain of education and specifically in the field of foreign language learning (EFL), students may face various obstacles such as, learning conditions, teachers' methodologies and behaviors, inappropriate materials, or lack of learning facilities or equipment. Consequently, tracing the antecedents of demotivation should be a focal issue for both teachers and researchers who are inspired to provide EFL students with the most suitable learning conditions. Sakai and Kikuchi (2009) identified six demotivators in EFL contexts, including teachers, characteristics of classes, and experiences of failure, class environment, class materials, and lack of interest. Each of these demotivators can diminish learners' desire and motivation towards learning.

The empirical demotivation-related studies encompass many dimensions in terms of the most significant factors leading to student demotivation. These studies have demonstrated that learners perceived motivation as a student-owned state, while grasping de-motivation as a teacher-owned problem (e.g., Chambers, 1999; Gorham \& Christophel, 1992; Ushioda, 1998;). Rudnai (1996) reported that lack of a pleasant and relaxed atmosphere, skilled teachers, and choice, as well as not being placed in the appropriate group of proficiency are the most important demotivators. Gorham and Millette (1997) also conducted a study with the same purpose and have found three categories including teachers' behaviours, context, and format/ structure. Classroom activities, teachers and students' conflicts, teachers' attitudes and behaviours were among important factors which diminished students' demotivation (Oxford, 1998). In a similar vein, Dörnyei (2001) demonstrated that characteristics of the course book, L2 community, teacher's methodology and personality, learning facilities, and interference of another language are among the crucial demotivators among students. In another study, demotivating factors were identified as follows: peers' negative attitudes toward learning, feeling of inferiority regarding one's ability, exam-oriented classes, lack of choice and control over the material being learned, and distrust in teachers' abilities (Ikeno, 2002).

Hasegawa (2004) found a significant relationship between inappropriate teachers' behaviors and students' de-motivation. Arai (2004) noted that monotonous classroom atmosphere and teachers' behavior are the most important demotivators. In line with the previous studies, Zhang (2007) identifies teachers' incompetence and indifference to the course and students, as well as unfair testing and boring presentations as significant demotivation factors. Other studies were carried out to find the relationship between student demotivation and some demographic variables such 
as age (e.g., Falout et al. 2009), gender, or proficiency level (e.g., Falout, Elwood, \& Hood, 2009; Falout \& Maruyama, 2004).

Despite the bulk of research exploring the most critical demotivators, the notion seems to be remained an unchartered territory among EFL learners. Only recently have EFL educationalists paid attention to the concept of student demotivation in relation to some other factors such as goal-orientation or contextual factors (e.g., Allahdadi et al. 2016; Ghanizadeh \& Jahedizadeh, 2016). In consideration of what was noted about the contributing role of student demotivation in learning process, the present study aims at exploring EFL students' demotivation by examining its association with learners' perceptions, mastery goal orientation, burnout, and achievement.

Perception, as one of the key factors studied in the present research, is defined as the process by which one receives and interprets information from the environment. Perceptions reflect one's emotions, expectations, and needs. In the domain of education, student perceptions of classroom activities comprising four main components namely; interest, challenge, choice, and joy (Gentry et al. 2002) have been identified as significant determinants of academic achievement (e.g., Ghanizadeh \& Jahedizadeh, 2015a; Mucherah \& Frazier, 2013) as well as student goal orientations (Ghanizadeh \& Jahedizadeh, 2015c). In other words, if students perceive the environment as supportive, their motivation will be enhanced. On the other hand, if students perceive the classroom environment as obstructive or feel marginalized, their motivation will be eroded (Jahedizadeh, Ghonsooly, Ghanizadeh, \& Akbari, 2015). Previous studies were carried out to find the relationship between student perception and some demographic variables such as gender and grade-level (e.g., Gentry et al. 2002), the subject area (Grossman \& Stodolsky, 1995), cognitive strategy use (Young, 1997), teachers' interpersonal behavior (Brok et al. 2004; Hardré \& Sullivan, 2007), epistemological beliefs and learning approaches (Ozkal et al. 2008), teacher support and involvement (Lee et al. 2009), and self-regulating learning and motivational beliefs (Kharrazi \& Kareshki, 2010).

Mastery goal orientation, as one of the components of the achievement goal orientation, is another factor studied in the present research. Generally speaking, goal orientation theory revolves around the ways students think about themselves, their performance on the tasks in the immediate learning situation and focuses on the central role of student perception of educational goals. A two factor model of achievement goals comprises two components, mastery and performance goal orientations in which the former is related to the standpoint where students are concerned with mastering their competence and the latter represents the state in which learners are concerned with merely displaying their competence relative to others (Ames, 1992; Dweck \& Leggett, 1988). Another model, however, added a third component to the previous pattern, i.e., avoidance goal orientation in which the main concern is hiding one's lack of ability relative to others (Elliot \& McGregor, 2001). Consequently, a tripartite model of achievement goal-orientation was proposed consisting of three dimensions. The first component (i.e., mastery goal) can represent the most ideal approach towards attaining academic objectives. Mastery goal-orientated learners face challenges, persevere in difficulties (Dweck, 2000), utilize elaboration strategies, and attain high levels of performance due to their intrinsic motivation (Elliott \& Dweck 1988).

A plethora of studies has been conducted to find the associations between student goal orientations in diverse educational contexts (e.g., Ghanizadeh et al. 2016) as well 
as some cognitive, affective, and psychological factors. Cognitive and metacognitive strategies (Pintrich \& DeGroot 1990) Cognitive and metacognitive strategies (Pintrich \& DeGroot 1990), perceptions of classroom and school environment and motivation (Dickinson, 1995), self-efficacy and self-confidence (Dweck \& Leggett, 1988), students' perception of classroom environment performance and intrinsic motivation (Church et al. 2001), self-efficacy (Jackson, 2002; Pajares, 2003), self-efficacy and metacognition components (Zafarmand et al. 2014), interest (Hulleman et al. 2010), achievement emotions (Huang, 2011), and demotivation (Jahedizadeh et al. 2015) were found to be significantly associated with student goal orientation.

Burnout as another factor pertained to the present study can be defined as a syndrome resulting from forms of chronic stress associated with frequent interactions and direct contact with others. The notion of burnout was first proposed by Freudenberger (1974) to refer to fixed job-related stress. According to the three dimensional model proposed by Maslach and Jackson (1986), there are three dimensions of burnout namely; emotional exhaustion, depersonalization, and reduced personal accomplishment. The first dimension of burnout can be characterized as the loss of energy, debilitation, fatigue, and wearing out. The second dimension of burnout (i.e., depersonalization) is the state of becoming indifferent to the people and ignoring the service recipients in order to put distance between themselves and oneself (Maslach \& Jackson, 1986). Reduced personal accomplishment as the third component of burnout is related to academic inefficacy when one feels exhausted or indifferent.

Although the notion of burnout was proposed with reference to working people in their work environment (e.g., Ghanizadeh \& Jahedizadeh, 2015b; Ghanizadeh \& Jahedizadeh, 2016), it can be generalizable to students as well (Pottage \& Huxley, 1996). Gender and educational level (Jahedizadeh, et al. 2015), lack of engagement (Schaufeli et al. 2002), personal lives, financial strain, difficult course content, and difficulty in balancing school and work (Darling et al. 2007), avoiding coping strategies (Gibbons, 2010), low spirituality (Wachholtz \& Rogoff, 2013), and extrinsic motivation and neuroticism (Reichl et al. 2014), attributions and self-regulatory strategies (Ghanizadeh \& Ghonsooly, 2014) were found to be the most important antecedents of student burnout.

Taken together, the role of the above-discussed constructs in effective learning has conclusively been demonstrated by educational researchers. Nevertheless, these constructs have been studied in parallel, and to the researchers' best knowledge, no empirical study to date has examined these variables within a single framework. Accordingly, it appears that there is a clear need for research in this area to probe how these factors interact in accounting for effective learning and emotional well-being.

\section{Purpose of the study}

The main purpose of this study is to delve into EFL students' demotivation by investigating its effect on other attributes including, student burnout, mastery goal orientation, perceptions of classroom activities, and their achievement. Viewed from a broader perspective, it seeks to examine and interpret the hypothesized relationships among these variables within a single framework. The findings are expected to pave the way to proposing a model for EFL learning and academic effectiveness. 
As education scholars have posited, demotivators as detrimental factors leading to diminishing motivational basis of an on-going action or behavioral intention have significant effects on eradicating both teacher and student effectiveness (e.g., Dörnyei, 2001). It is also contended that de-motivation is not a permanent issue which implies demotivated learners can rehabilitate their motivation, a phenomenon known as remotivation (Falout, 2012; Ushioda, 1998;). Consequently, studying such deleterious factors should be a compelling priority for educationalists given that they are critical in students' perceptions of their classroom and burnout (Ghanizadeh \& Jahedizadeh, 2016), as well as their goal orientation and achievement (Allahdadi, et al., 2016). In line with this, a number of prominent scholars in the domain of student demotivation have maintained that this concept is pivotal to the student motivation in that exploring the causes of de-motivation can help researchers with theories of the positive side, i.e., motivation (e.g., Sakai \& Kikuchi, 2009).

Figure 1 represents our hypothesized model proposed based on the theoretical contentions discussed earlier. Structural equation modeling (SEM) was selected to study the involved causal relationships. In the proposed model, demotivators constitute the core of the study and their direct and indirect roles in the other four variables are investigated. The demotivators measured in this study are as follows: (1) TEA: teachers; (2) COC: characteristics of classes; (3) CEN: classroom environment; (4) CMA: classroom materials; (5) LOI: lack of interest, and (6) EOF: experiences of failure. These demotivators were set as the independent variables; the first four variables are considered as external demotivators and the last two factors are internal ones. The influence of each of these demotivators on student burnout was examined. Moreover, the effect of two internal demotivators on student mastery goal orientation was explored. The effect of student burnout on mastery goal orientation, as well as student perceptions, in line with the effect of student perceptions on mastery goal orientation were hypothesized. Also, the influence of student perceptions of classroom activities on student achievement was estimated. As it will be discussed in the next section, student

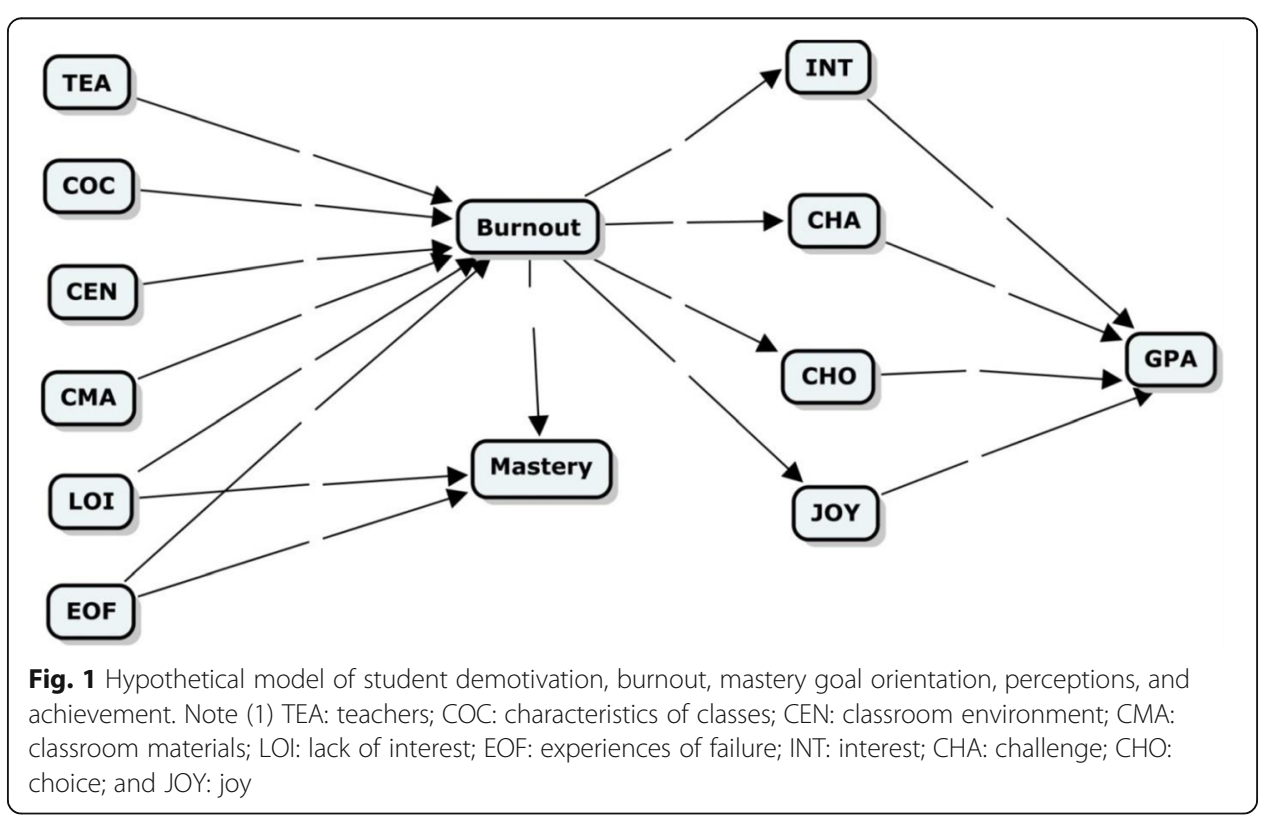


perceptions of classroom activities as measured in the present study comprise four subscales: (1) INT: interest; (2) CHA: challenge; (3) CHO: choice, and (4) JOY: enjoyment. The arrows depict the direction of the relationship among these variables.

\section{Method}

Participants

The participants of the present study comprised 250 EFL students selected according to convenience sampling among EFL learners studying English in language institutes and universities in Mashhad, a city in Iran. After a brief explanation of the purpose of the research, all the participants received the student demotivation scale, student burnout inventory, achievement goal orientation inventory, and student perceptions of classroom activities questionnaire and then completed them. In order to obtain reliable data, the researchers explained the purpose of completing the questionnaires and assured the participants that their responses would be kept confidential by asking them not to write their names. They were only required to provide demographic information such as gender, age, and education level; however, writing their GPA was obligatory to receive student achievement. The four scales contained about 87 items and it took about $20 \mathrm{~min}$ to answer all the items. The accessibility of the questionnaires in the respondents' native language (Persian) added to speed with which they responded to the items. To get more reliable and accessible responses, the questionnaires were given together in a single session.

The profile of the students is as follows. Out of 250 students 125 of them were studying English in language institutes and 125 participants were university students. Their age varied from 19 to 32 years old ( $m e a n=24$, standard deviation $=3.78$ ). Out of 250 students, 32 students held a diploma, 184 had a bachelor of arts (BA), 34 held a master of arts (MA). Female participates were 161, while 89 were male.

\section{Instrumentation}

A battery of four questionnaires was utilized in the present study as follows.

\section{Demotivation scale}

To determine student demotivation, the study employed the Persian version of 'demotivation scale' designed and validated by Sakai and Kikuchi (2009) and translated to Persian by Ghanizadeh and Jahedizadeh (2016). The de-motivation questionnaire consists of 35 statements gauging six demotivators: teachers (6 items), characteristics of classes ( 7 items), class environment ( 7 items), class materials (6 items), lack of interest (4 items), and experiences of failure (5 items). The scale measures the six constructs via a 5-point Likert-type response format (not true, to some extent not true, not either true or untrue, to some extent true and true).

The Persian version of the questionnaire translated and validated by Ghanizadeh and Jahedizadeh (2016) enjoyed acceptable validity and reliability estimates. The validity indices computed via CFA were as follows: the chi-square/df ratio $=2.1$, the RMSEA $=.062$, NFI $=.90, \mathrm{GFI}=.89$, and CFI $=.91$. The Cronbach's alpha estimate for all six de-motivators was found to be .95 regarding 35 items. The reliability of the subscales ranged from .72 to .87 (teachers $=.87$, characteristics of classes $=.72$, experiences of failure $=.84$, class environment $=.72$, class materials $=.82$, and lack of interest $=.87$ ). 


\section{Burnout inventory}

The Persian version of Maslach Burnout Inventory Student-Survey (MBI-SS) designed and validated by Schaufeli et al. (2002) was used to determine EFL student burnout. The scale comprises 15 items evaluating three dimensions of burnout: emotional exhaustion (5 items), cynicism ( 4 items), and academic efficacy (6 items). The scale measures the three constructs via a 5-point Likert-type response format (never, seldom, sometimes, often, and always). The Persian version of the scale - translated and validated by Rostami, Abedi, and Schaufeli (2012) - demonstrated acceptable reliability indices in which Coefficient Cronbach's alpha for emotional exhaustion, cynicism, and academic efficacy were $0.88,0.90$, and 0.84 respectively.

\section{Achievement Goal Orientation Inventory (AGOI)}

Students' mastery goal orientation was measured by the translated version of Achievement Goal Orientation Inventory designed by Midgley et al. (1998). The inventory comprises three subscales, 6 items for each goal orientation and a total of 18 items, and allows responses ranging from 1 (not at all true of me) to 7 (very true of me). Table 1 represents three possible goal orientations.

The Persian version of the scale-translated and validated by Rezaee and Kareshki (2012)-depicted acceptable reliability indices $(.81, .89, .83$, respectively). The results of CFA confirmed the validity of the translated version (GFI $=.92, \mathrm{AGFI}=.88$, RMSEA = .07). In the present study, the reliability indices computed via Cronbach's alpha were found to be as follows: mastery $=.75$, performance $=.72$, and avoidance $=.71$.

\section{Students' perceptions of classroom activities}

To determine student perceptions of classroom activities, Persian version of 'Students Perceptions of Classroom Activities' scale designed and validated by Gentry and Gable (2001) and translated to Persian by Ghanizadeh and Jahedizadeh (2015a) was utilized.

The 'Students Perceptions of Classroom Activities' instrument contains 31 statements evaluating four dimensions (interest, challenge, choice, and enjoyment). The scale measures the four dimensions via a 5-point Likert-type response format (never, seldom, sometimes, often, always). As reported by Gentry et al. (2002), the instrument was piloted and a confirmatory study was undertaken for a national sample. Validity evidence for construct interpretation was investigated through CFA. A GFI of .95 and a RMSEA of .04 were indicative model fit. Item response theory was used to examine the adequacy of the definition of each construct including how well the 5-point frequency response scale worked for the items and respondents. The Persian version of the scale was also indicative model fit. A GFI of .78 and a RMSEA of .062 were obtained.

Sample items for 'interest' dimension included: 1) The teacher involves me in interesting learning activities, and 2) What I do in my class gives me interesting and new

Table 1 Subscales of the AGOI along with the corresponding descriptions

\begin{tabular}{llll}
\hline Subscale & Definition & Alpha & Items \\
\hline Mastery-approach & Attaining task-based or intrapersonal competence & .85 & $1-6$ \\
Performance-approach & Attaining normative competence & .89 & $7-12$ \\
Performance-avoidance & Avoiding normative incompetence & .74 & $13-18$ \\
\hline
\end{tabular}


ideas. Sample items for 'challenge' dimension are: 1) I have to think to solve problems in my class, and 2) What we do in class fits my abilities. Sample items include in 'choice' dimension are: 1) When we work together, I can choose my partners, and 2) When there are many jobs, I can choose the ones that suit me. Sample items for 'joy' dimension are :1) The teacher makes learning fun, and 2) I like what I do in my class.

\section{Results}

Table 2 presents descriptive statistics of demotivators. Throughout this study, TEA stands for teachers, COC stands for characteristics of classes, EOF for experience of failure, CEN for classroom environment, CMA for characteristics of materials, and LOI for lack of interest. As the table indicates, $C O C$ receives the highest mean $(M=23.87$, $S D=4.34)$ followed by CEN $(M=23.40, S D=5.03)$.

Table 3 shows descriptive statistics of perceptions of classroom activities. Here, INT represents interest, $\mathrm{CHA}$ stands for challenge, $\mathrm{CHO}$ for choice, and Joy for enjoyment. According to the table, CHA obtains the highest mean $(M=31.12, S D=4.14)$ and CHO the lowest mean score $(M=23.21, S D=3.43)$.

Descriptive statistics of perceptions of burnout, mastery, and language achievement (as measured by GPA) are represented in Table 3. As the table displays, mean score of burnout is 43.03 , for mastery, it is 22.42 , and for GPA, it is 16.83 .

The reliability estimates of each variable computed via Cronbach's alpha are as follows: TEA $(\alpha=.74)$, COC $(\alpha=.71)$, EOF $(\alpha=.69)$, CEN $(\alpha=.65)$, CMA $(\alpha=.67)$, LOI $(\alpha=.69)$, INT $(\alpha=.71)$, CHA $(\alpha=.70)$, CHO $(\alpha=.62)$, JOY $(\alpha=.75)$, Burnout $(\alpha=.81)$, Mastery $(\alpha=.66)$, and GPA $(\alpha=.73)$.

To examine the structural relations, the proposed model was tested using the LISREL 8.50 statistical package. A number of fit indices were examined to evaluate the model fit: the chi-square magnitude which shouldn't be significant, Chi-square/ $d f$ ratio which should be lower than 2 or 3, the normed fit index (NFI), the good fit index (GFI), and the comparative fit index (CFI) with the cut value greater than .90 , and the Root Mean Square Error of Approximation (RMSEA) of about .06 or .07 (Schreiber, et al., 2006).

As demonstrated by Fig. 2, the fit indices are slightly below those thresholds: GFI (.89) RMSEA (.89) and the chi-square/df ratio (5.58). This implies that the model had a moderate fit with the empirical data.

To reach a better model fit, a post-hoc modification was then conducted. In so doing, a path coefficient from mastery to GPA and covariances between mastery perceptions were inserted in the model. This resulted in an overall fit

Table 2 Descriptive statistics of demotivators

\begin{tabular}{llllll}
\hline & N & Minimum & Maximum & Mean & Std. deviation \\
\hline TEA & 250 & 6.00 & 26.00 & 17.7560 & 5.69581 \\
COC & 250 & 11.00 & 33.00 & 23.8720 & 4.34640 \\
EOF & 250 & 5.00 & 22.00 & 15.3120 & 4.45038 \\
CEN & 250 & 8.00 & 32.00 & 23.4040 & 5.03888 \\
CMA & 250 & 6.00 & 27.00 & 18.6040 & 4.80954 \\
LOI & 250 & 2.00 & 10.00 & 5.5360 & 2.18995 \\
Valid N (listwise) & 250 & & & & \\
\hline
\end{tabular}


Table 3 Descriptive statistics of perceptions of classroom activities

\begin{tabular}{llllll}
\hline & N & Minimum & Maximum & Mean & Std. deviation \\
\hline INT & 250 & 18.00 & 40.00 & 29.1480 & 4.00478 \\
CHA & 250 & 19.00 & 41.00 & 31.1200 & 4.14613 \\
CHO & 250 & 14.00 & 33.00 & 24.2120 & 3.43720 \\
JOY & 250 & 14.00 & 35.00 & 25.4840 & 3.90368 \\
Valid N (listwise) & 250 & & & & \\
\hline
\end{tabular}

improvement: chi-square $=65.12$, the chi-square $/ d f$ ratio (3), RMSEA $=.66$, GFI $=.92$, $\mathrm{NFI}=.90$, CFI $=.90$. Figure 3 represents the model.

To check the strengths of the causal relationships among the variables, the $t$-values and standardized estimates were examined. As indicated in Fig. 2, two estimates were displayed on the paths. The first one is the standardized coefficient $(\beta)$ which explains the predictive power of the independent variable and presents an easily grasped picture of effect size. The closer the magnitude to 1.0, the higher the correlation and the greater the predictive power of the variable is. The second measure is the $t$-value $(\mathrm{t})$; if $t>2$ or $t<-2$, we call the result statistically significant.

The results demonstrated that among the demotivators, all had positive significant impact on burnout except $\operatorname{COC}(\beta=.14, t=1.93)$. The highest influence was exerted by CMA $(\beta=.38, t=5.48)$, followed by LOI $(\beta=.36, t=5.40)$. EOF influenced mastery negatively $(\beta=.46, t=-2.28)$. Burnout also had a negative impact on mastery $(\beta=-.43, t=-3.45)$. Two perceptions were negatively predicted by burnout: INT $(\beta=-.40, t=-6.83)$ and JOY $(\beta=-.45, t=-7.84)$. All four perceptions positively predicted GPA with INT and JOY having the highest impacts: INT $(\beta=.38, t=5.55)$, JOY $(\beta=.33, t=5.05)$, CHA $(\beta=.20, t=2.11)$, and $\mathrm{CHO}(\beta=.46, t=6.83)$. Mastery was also a positive predictor of GPA $(\beta=.23, t=3.01)$. Tw perceptions, namely INT and JOY, exerted a positive and significant impact on mastery: INT $(\beta=.33, t=5.23)$ and JOY $(\beta=.21$, $t=3.14)$.

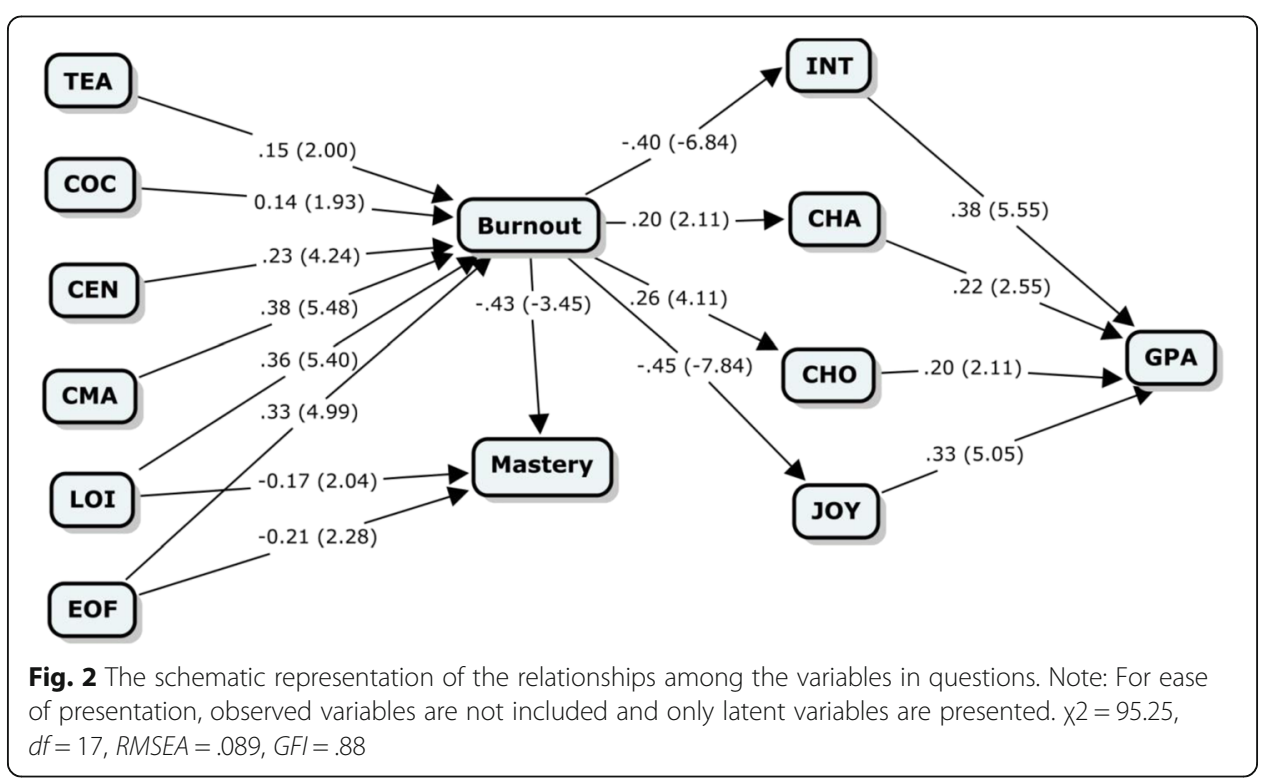




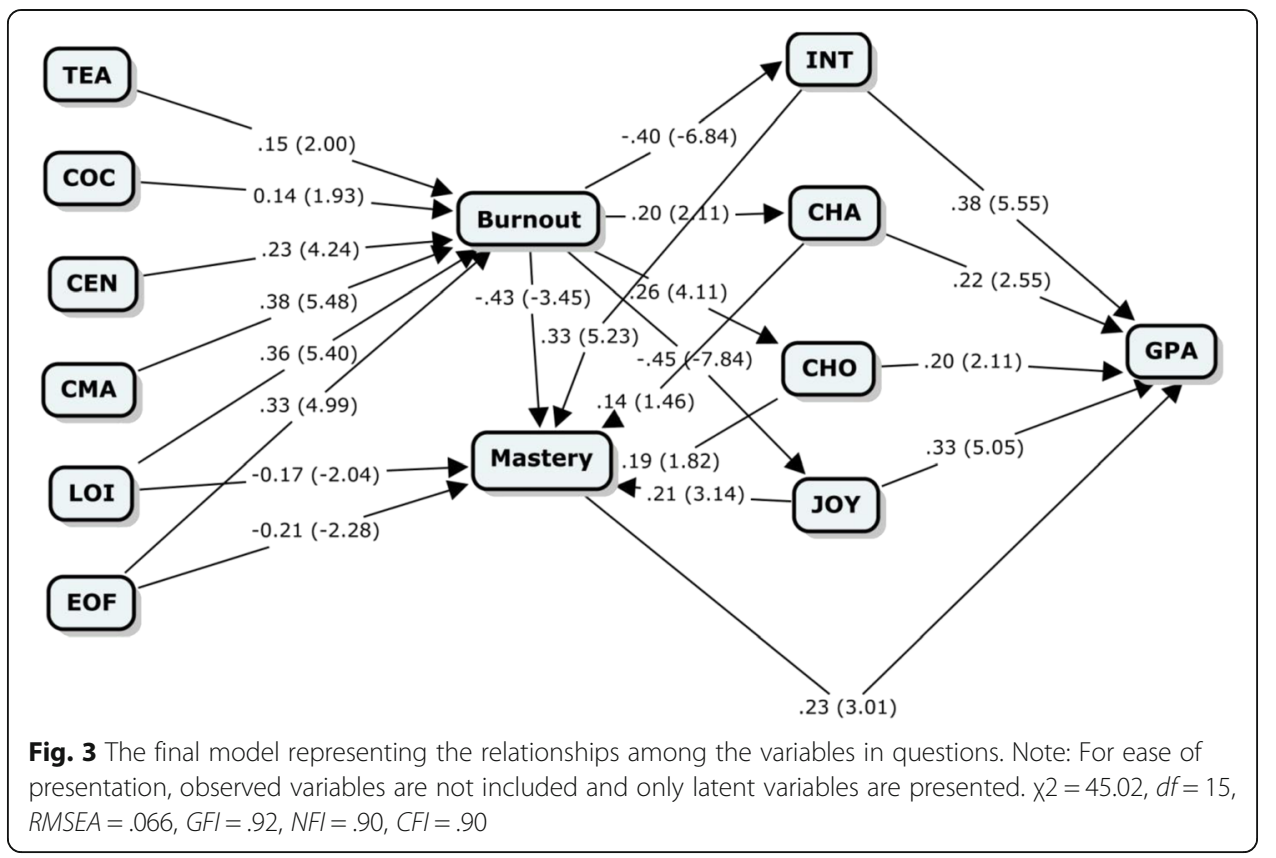

The correlation coefficients among the variables in question are presented in Table 4. As it can be seen, the highest correlations were observed between demotivators and burnout: CEN $(r=0.67, p<0.05)$, LOI $(r=0.64, p<0.05)$, EOF $(r=0.63, p<0.05)$, and TEA $(r=0.60, p<0.05)$. Concerning the nexus between demotoivators and perceptions, mixed results were obtained. Significant negative correlations were found between demotivators and perceptions of INT and JOY with the highest associations between LOI and INT $(r=-0.72, p<0.05)$, and between LOI and JOY $(r=-0.63, p<0.05)$. GPA had the highest correlations with TEA $(r=-0.54, p<0.05)$, INT $(r=0.51, p<0.05)$, and mastery $(r=0.49, p<0.05)$.

\section{Discussion}

The present study aimed at investigating the direct and indirect role of student demotivation in student burnout, student mastery goal orientation, student perceptions of classroom activities, and student achievement. In effect, this study sought to find the effects of demotivators on student burnout, two internal demotivators and student burnout on student mastery goal orientation, student burnout on student perceptions of classroom activities, student perceptions on mastery goal orientation, and student perceptions and mastery goal orientation on student achievement.

As it is illustrated in Table 5 the results indicated that five out of six demotivators predicted student burnout positively and significantly. In particular, class materials, lack

Table 4 Descriptive statistics of burnout, mastery, and language achievement

\begin{tabular}{llllll}
\hline & $N$ & Minimum & Maximum & Mean & Std. deviation \\
\hline Burnout & 250 & 15.00 & 63.00 & 43.0360 & 8.33358 \\
Mastery & 250 & 8.00 & 30.00 & 22.4240 & 3.92861 \\
GPA & 250 & 12.80 & 20.00 & 16.8389 & 1.57517 \\
Valid N (listwise) & 250 & & & & \\
\hline
\end{tabular}


Table 5 The correlation coefficients among demotivators, perceptions, language achievement, mastery, and burnout

\begin{tabular}{|c|c|c|c|c|c|c|c|c|c|c|c|c|c|}
\hline & 1 & 2 & 3 & 4 & 5 & 6 & 7 & 8 & 9 & 10 & 11 & 12 & 13 \\
\hline 1. TEA & 1.00 & & & & & & & & & & & & \\
\hline 2. $\operatorname{coc}$ & $.69^{a}$ & 1.00 & & & & & & & & & & & \\
\hline 3. EOF & $.75^{\mathrm{a}}$ & $.68^{\mathrm{a}}$ & 1.00 & & & & & & & & & & \\
\hline 4. CEN & $.55^{\mathrm{a}}$ & $.57^{\mathrm{a}}$ & $.50^{\mathrm{a}}$ & 1.00 & & & & & & & & & \\
\hline 5. CMA & $.74^{\mathrm{a}}$ & $.63^{\mathrm{a}}$ & $.72^{\mathrm{a}}$ & $.51^{\mathrm{a}}$ & 1.00 & & & & & & & & \\
\hline 6. LOI & $.66^{a}$ & $.62^{\mathrm{a}}$ & $.73^{a}$ & $.51^{\mathrm{a}}$ & $.65^{a}$ & 1.00 & & & & & & & \\
\hline 7. INT & $-.31^{\mathrm{a}}$ & $-.32^{a}$ & $-29^{a}$ & $-.41^{\mathrm{a}}$ & $-.39^{a}$ & $-.72^{a}$ & 1.00 & & & & & & \\
\hline 8. $\mathrm{CHA}$ & $.40^{\mathrm{a}}$ & $.38^{\mathrm{a}}$ & $.42^{\mathrm{a}}$ & .13 & $.41^{\mathrm{a}}$ & $.35^{\mathrm{a}}$ & $.43^{\mathrm{a}}$ & 1.00 & & & & & \\
\hline 9. $\mathrm{CHO}$ & $.24^{a}$ & $.25^{\mathrm{a}}$ & $.24^{\mathrm{a}}$ & .18 & $.27^{\mathrm{a}}$ & $.25^{\mathrm{a}}$ & $.48^{\mathrm{a}}$ & $.57^{\mathrm{a}}$ & 1.00 & & & & \\
\hline 10. JOY & $-.36^{a}$ & $-.31^{\mathrm{a}}$ & $-29^{a}$ & $-.45^{\mathrm{a}}$ & $-.28^{a}$ & $-.63^{a}$ & $.80^{\mathrm{a}}$ & $.32^{a}$ & $.505^{\mathrm{a}}$ & 1.00 & & & \\
\hline 11. GPA & $-.54^{\mathrm{a}}$ & $-.45^{a}$ & $-.39^{a}$ & $-.47^{a}$ & $-.32^{a}$ & $-.48^{a}$ & $.51^{\mathrm{a}}$ & $.28^{\mathrm{a}}$ & $.31^{\mathrm{a}}$ & $.46^{\mathrm{a}}$ & 1.00 & & \\
\hline 12. MAS & $-.28^{a}$ & $-.21^{\mathrm{a}}$ & $-.31^{\mathrm{a}}$ & $-.32^{a}$ & $-.29^{a}$ & $-.33^{a}$ & $.56^{\mathrm{a}}$ & $.30^{a}$ & $.36^{\mathrm{a}}$ & $.53^{\mathrm{a}}$ & $.49^{a}$ & 1.00 & \\
\hline 13. $B R$ & $.60^{\mathrm{a}}$ & $.48^{\mathrm{a}}$ & $.63^{a}$ & $.67^{\mathrm{a}}$ & $.51^{\mathrm{a}}$ & $.64^{\mathrm{a}}$ & $-.40^{a}$ & $.26^{\mathrm{a}}$ & .15 & $-.45^{a}$ & $-.39^{a}$ & $-.31^{a}$ & 1.00 \\
\hline
\end{tabular}

${ }^{a}$ Correlation is significant at the level of 0.05

of interest, experiences of failure, classroom environment, and teachers influenced burnout in a positive and significant direction. No significant relationship, nevertheless, was found between characteristics of classes and student burnout. Class materials as the most important demotivator influencing student burnout consist of various references which are used to teach students, such as; textbook, hand-outs, etc. If the materials are not interesting, up to dated, or in accordance with the needs of students, it will lower learners' motivation and consequently causes burnout, given that one the most important determinants of educational burnout is the loss of affective attachment with the classroom setting and the subsequent decline in engagement on the part of students. Too many hand-outs or reference books, for instance, can be characterized as demotivators in terms of class materials (Arai, 2004; Falout \& Maruyama, 2004; Gorham \& Christophel, 1992; Christophel \& Gorham, 1995; Gorham \& Millette, 1997; Kojima, 2004).

Lack of interest as the second important demotivator affecting student burnout is related to the sense that English used in the learning environment is not necessary and practical. This negative attitude leads to little admiration towards English speaking people (Falout \& Maruyama, 2004; Ikeno, 2002; Tsuchiya 2004a, b, 2006a, b). If students are not interested in the language they are learning or the environment in which they are studying a new language, it will result in burnout development. In other words, burnout is manifested through behavioral reactions including poor performance, tardiness, absenteeism, and lack of interest. The third significant demotivator in burnout development, according to this study, is student experiences of failure which can be defined in terms of disappointment caused by low test scores, lack of acceptance by teachers, and inability to memorize idioms or vocabularies (Gorham \& Christophel, 1992; Gorham \& Millette, 1997; Tsuchiya 2004a, b, 2006a, b;). The association between this demotivator and student burnout can also be found in other studies in harmony with the current research (e.g., Linden et al. 2005). Classroom environment as the fourth factor of demotivation influencing student burnout is characterized by friends' 
and classmates' attitudes, compulsory nature of the course, passive classes, inadequate school facilities, and inappropriate level of the lessons (Falout \& Maruyama, 2004). Undoubtedly, such conditions aid to the development of student burnout, especially the emotional side of the syndrome (Dorman, 2003). The last important demotivator which was significantly associated with student burnout was found to be teachers which comprisesmany factors attributed to teachers such as; teachers' language proficiency, personality, methodology, teaching style, attitude, and competence (Arai, 2004; Ikeno, 2002; Zhang, 2007). If teacher attributed features are not in harmony with student expectations and desires, students will feel degrees of burnout which is not necessarily intentional or conscious and maybe due to teacher burnout. Accordingly, when emotionally exhausted teachers are not actively and enthusiastically involved in organizing classroom time and in devising tasks and activities, and when they do not invest energy and creativity in their endeavors, this mood would normally be reflected in the classroom and depreciate students' efforts, attitudes, and motivation. Furthermore, when teachers develop impersonal perception of students they do not normally pay enough attention to their students' concerns and attitudes thereby impinging on learners' sense of attachment to the classroom, as well as their motivation to learn. Consistent with this contention, Ghanizadeh and Royaei (2015) found that if teachers do not pay enough attention to their students' concerns, learners will lose their motivation and consequently feel burnout by preferring loneness rather than interacting with others and passing the tests instead of learning language to use it communicatively.

The only demotivator which appeared to be unrelated to student burnout was the 'characteristics of classes' which is related to exam focused lessons and emphasizes on memorization of language (Gorham \& Millette, 1997; Zhang, 2007). The finding can be related to the nature of EFL learning situations and expectations which students are required to achieve. In other words, the focus of teachers and educational system in most academic institutions (from primary schools to higher education) in Iran is on students' grades, and learners normally get accustomed to this learning approach. Consequently, they prefer focusing on exams and grades as their motivational basis and are satisfied with the situation (Nowell, 2007).

The results also indicated that the two internal demotivators namely; experiences of failure and lack of interest affect student mastery goal orientation negatively and significantly. In other words, if students face some failure regarding EFL learning or are not interested in their learning experience, they won't adapt mastery approach as their goal orientation which is learning the language for mastering one's competence. The findings can be justified in accordance with previous studies demonstrating negative associations between student mastery goal orientation and student anxiety and negative attitudes - as the common ramifications of student demotivation (e.g., Cury et al. 2002; Elliot \& McGregor, 1999; Kumar \& Jagacinski, 2006; McGregor \& Elliot, 2002; Middleton \& Midgley, 1997; Pajares \& Cheong, 2003; Sideridis, 2005a; Skaalvik, 1997; ). A recent study among EFL learners also reported the same finding by indicating a positive relationship between student avoidance goal orientation - as opposed to mastery approach - and student demotivation (Allahdadi et al. 2016). 
The findings also demonstrated a negative relationship between student burnout and student mastery goal orientation. In other words, if students experience burnout syndrome, they are likely to avoid adapting mastery approach as their goal of EFL learning. This finding substantiates other studies (e.g., Erfani \& Maleki, 2015; Mousavi \& Ghafelehbashi 2015; Shan \& Jiang, 2012; Zahed et al. 2014; ). Moreover, a positive effect of student mastery goal orientation on student GPA was observed. According to this finding, students who adapt mastery approach towards their learning get high scores which are the indicators of academic achievement. A plethora of studies has conclusively corroborated this finding (e.g., Fatima \& Salma, 2012; Leondari \& Gonida, 2008; Mattern, 2005; Yildirim, 2004; Zafarmand et al. 2014).

As another finding of the present study, it was also shown that student burnout has a negative influence on all the constructs of student perceptions of classroom activities, namely; joy, interest, choice, and challenge, respectively. In other words, if students undergo burnout, they no longer perceive their classroom activities as enjoyable, interesting, varied, and challenging. This is indeed detrimental to the learning situation, since students would not enjoy the experience, even though their class activities are suitably selected and organized. In effect, the experiences of burnout can be described in terms of helplessness, hopelessness, somatic complaints, and negative self-concept as well as negative perceptions towards the community and environment (Belcastro 1982; Maslach 1976; Pines \& Kafry 1978;). Accordingly, low burnout score of an individual is the indicator of more positive attitudes and perceptions whereas high level of burnout is the predictor of unfavourable attitudes (Astrom, 1990). Consistent with this standpoint, Rostami et al. (2012) found a negative association between student burnout and interest. In another study, Kuittinen, and Meriläinen (2014) investigated the frequency of studyrelated burnout with respect to student motivation and students' perceptions regarding learning environment. The findings revealed drastic deterioration of students' perceptions due to their burnout.

The SEM analysis also revealed the significant role of students' perceptions of interest and joy on their mastery goal orientation. In other words, students with higher interest and joy towards their classroom activities are more inclined for adapting mastery goal orientation. The fact that being interested in a topic dramatically contributes to better achievement and performance is undeniable (Hidi, 1990). Interest and joy towards some particular issue - classroom activities, for instance - promote attention, recall, effort, and achievement (Ainley et al. 2002; Hidi \& Renninger, 2006). Consequently, if students perceive their learning environment as supportive and feel included, their motivation will be enhanced and mastery goal orientation will be adapted. The aforementioned finding corresponds with the previous empirical studies (e.g., Dickinson, 1995; Church et al. 2001; McGregor \& Elliot, 2002; Harackiewicz et al. 2002; Flum \& Kaplan, 2006; Shen et al. 2007; Pekrun et al. 2009; Hulleman et al. 2010; Huang, 2011; Ghanizadeh \& Jahedizadeh, 2015a).

Finally, it was found that students' perceptions of interest and joy positively and significantly predicted students' achievement. It implies if learners perceive their classroom activities as interesting and joyful, their GPA as the indicator of learners' success and achievement will be enhanced as well. The results are in line with previous studies (e.g., Dickinson, 1995; Lizzio et al. 2002; Ghanizadeh \& Jahedizadeh, 2015a). 


\section{Conclusions}

Taken together, the findings of this study put forward the prospect of developing a multidimensional understanding of student demotivation and its effect on four constructs including; student burnout, student mastery goal orientation, student perceptions of classroom activities, and student achievement. As Dörnyei (2001) contended, demotivators as the specific external forces can reduce or diminish motivational basis of a behavioural intention, as well as an ongoing action.

Our proposed model highlighted the direct and indirect role of demotivators in giving rise to student burnout and inhibiting student mastery goal orientation, positive perceptions of classroom activities, and student achievement. This finding in turn can have crucial implications for SLA research, in general, and EFL student learning, in particular. It should, in the first place, inform both teachers and students of debilitative sources of student demotivation and help them in ameliorating learning process. Teachers are responsible for identifying students' interests and adapting methodologies, materials, and learning environment according to students' needs and preferences leading to positive perceptions of classroom activities which in turn affect student goal orientation and academic achievement. In addition, students should know that adapting a realistic goal for their learning can be influenced by many factors among which burnout and perceptions play vital roles.

The present study is limited in a number of ways. First, the participants were chosen according to convenience sampling due to feasibility considerations. Second, the participants of the present study comprised EFL students in universities. Thus, the study should be replicated with samples from private language institutes and schools in different parts of the country which implies a higher degree of randomization and generalizability. Third, in this research, the proposed variables in question were assessed via questionnaires and no qualitative approach such as interviews, case study, or observation was used.

\footnotetext{
Authors' contributions

This work was carried out in collaboration between all authors. Author SJ (author 1) collected the data, wrote the first draft of the manuscript, participated in its design, and implemented the revisions. AG (author 2) supervised the work, decided upon and provided the sources, performed the statistical analyses, and revised and edited the first draft. Author BG (author 3) revised the first draft and advised on the procedure. All authors read and approved the final manuscript.
}

Competing interests

The authors declare that they have no competing interests.

\section{Author details}

${ }^{1}$ Imam Reza International University, Mashhad, Iran. ${ }^{2}$ Ferdowsi University of Mashhad, Mashhad, Iran.

Received: 27 April 2016 Accepted: 27 October 2016

Published online: 08 November 2016

References

Ainley, M., Hidi, S., \& Berndorff, D. (2002). Interest, learning, and the psychological processes that mediate their relationship. Journal of Educational Psychology, 94(3), 545-561.

Allahdadi, S., Jahedizadeh, S., Ghzanizadeh, A., \& Hosseini, A. (2016). On the impact of achievement goal-orientations on EFL university students' demotivation. International Journal of Educational Investigations, 3(1), 103-114.

Ames, C. (1992). Classrooms: Goals, structures, and student motivation. Journal of Educational Psychology, 84(3), $261-271$.

Arai, K. (2004). What 'demotivates' language learners? Qualitative study on demotivational factors and learners' reactions. Bulletin of Toyo Gakuen University, 12, 39-47.

Astrom, S. (1990). Attitudes, empathy and burnout among staff in geriatric and psychogeriatric care. Huddinge: Sweden: Umeå university medical dissertations.

Belcastro, P. A. (1982). Burnout and its relationship to teachers" somatic complaints and illnesses. Psychological Reports, 50, 1045-1046. 
Brok, P., Brekelmans, M., \& Wubbels, T. (2004). Interpersonal teacher behaviour and student outcomes. School Effectiveness and School Improvement, 15, 407-442.

Chambers, G. N. (1999). Motivating Language Learners (No. 12). Clevedon: Multilingual Matters.

Christophel, D., \& Gorham, J. (1995). A test-retest analysis of student motivation, teacher immediacy and perceived sources of motivation and demotivation in college classes. Communication Education, 44, 292-306.

Church, M. A., Elliot, A. J., \& Gable, S. A. (2001). Perceptions of classroom environment, achievement goals and achievement outcomes. Journal of Educational Psychology, 93(1), 43-54.

Cury, F., Elliot, A., Sarrazin, P., Da Fonseca, D., \& Rufo, M. (2002). The trichotomous achievement goal model and intrinsic motivation: A sequential mediational analysis. Journal of Experimental Social Psychology, 38, 473-481.

Darling, C. A., McWey, L. M., Howard, S. N., \& Olmstead, S. B. (2007). College student stress: The influence of interpersonal relationships on sense of coherence. Stress and Health, 23, 215-229.

Dickinson, L. (1995). Autonomy and motivation: A literature review. System, 23(2), 165-174.

Dorman, J. (2003). Relationship between school and classroom environment and teacher burnout: A LISREL analysis. Social Psychology of Education, 6, 107-127.

Dörnyei, Z. (2001). Teaching and researching motivation. Harlow: Longman.

Dörnyei, Z., \& Ottó, I. (1998). Motivation in action: A process model of L2 motivation. Working Papers in Applied Linguistics, 4, 43-69.

Dweck, C. S. (2000). Self-theories: Their role in motivation, personality, and development. Lillington: NC Taylor \& Francis.

Dweck, C. S., \& Leggett, E. L. (1988). A social-cognitive approach to motivation and personality. Psychological Review, 95, 256-73.

Elliott, E. S., \& Dweck, C. (1988). Goals: An approach to motivation and achievement. Journal of Personality and Social Psychology, 54, 5-12.

Elliot, A. J., \& McGregor, H. A. (1999). Test anxiety and the hierarchical model of approach and avoidance achievement motivation. Journal of Personality and Social Psychology, 76, 628-644.

Elliot, A. J., \& McGregor, H. A. (2001). A 2X2 achievement goal framework. Journal of Personality and Social Psychology, $80,501-519$.

Erfani, N., \& Maleki, H. (2015). Predicting academic burnout based on attribution styles and goal orientation of female students. International Journal of Innovation and Research in Educational Sciences, 2(1), 37-42.

Falout, J. (2012). Coping with demotivation: EFL learners' remotivation processes. The Electronic Journal for English as a Second Language, 16(3), 1-29.

Falout, J., Elwood, J., \& Hood, M. (2009). Demotivation: Affective states and learning outcomes. System, 37, $403-417$.

Falout, J., \& Maruyama, M. (2004). A comparative study of proficiency and learner demotivation. The Language Teacher, 28, 3-9.

Fatima, G., \& Salma, H. (2012). Achievement goal orientation and academic performance in undergraduate students. Pakistan Journal of Social and Clinical Psychology, 9(3), 112-139.

Flum, H., \& Kaplan, A. (2006). Exploratory orientation as an educational goal. Educational Psychologist, 41, 99-110.

Freudenberger, H. J. (1974). Staff burn-out. Journal of Social Issues, 30(1), 159-165.

Gentry, M., \& Gable, R. K. (2001). My class activities: A survey instrument to assess students' perceptions of interest, challenge, choice, and enjoyment in their classrooms. Mansfield Center: Creative Learning Press.

Gentry, M., Gable, R. K., \& Rizza, M. G. (2002). Students perceptions of classroom activities: are there grade-level and gender differences. Journal of Educational Psychology, 94, 539-544.

Ghanizadeh, A., \& Ghonsooly, B. (2014). A tripartite model of EFL teacher attributions, burnout, and self-regulation: Toward the prospects of effective teaching. Educational Research for Policy and Practice, 13, 145-166. doi:10.1007/ s10671-013-9155-3.

Ghanizadeh, A., \& Jahedizadeh, S. (2015a). Context-specific dynamics of demotivators in foreign language education. International Journal of Research Studies in Language Learning, 5 (2), 87-96.

Ghanizadeh, A., \& Jahedizadeh, S. (2015b). Teacher burnout: A review of sources and ramifications. British Journal of Education, Society \& Behavioural Science, 6(1), 24-39.

Ghanizadeh, A., \& Jahedizadeh, S. (2015c). An exploration of EFL learners' perceptions of classroom activities and their achievement goal orientations. International Journal of Research Studies in Education, 4 (3), 33-45.

Ghanizadeh, A., \& Jahedizadeh, S. (2015d). De-motivators and their association with burnout and language achievement in an Iranian EFL context. Journal of Teaching Language Skills, 7 (3), 61-85.

Ghanizadeh, A., \& Jahedizadeh, S. (2016). EFL teachers' teaching style, creativity, and burnout: A path analysis approach. Cogent Education, 3(1), 1-17.

Ghanizadeh, A., Jahedizadeh, S., \& Allahdadi, S. (2016). EFL learners' goal-orientation: A cross-contextual analysis. Journal of Global Research in Education and Social Science, 7(2), 108-114.

Ghanizadeh, A., \& Royaei, N. (2015). Emotional facet of language teaching: Emotion regulation and emotional labor strategies as predictors of teacher burnout. International Journal of Pedagogies and Learning, 10(2), 139-150. doi:10.1080/22040552.2015.1113847.

Gibbons, C. (2010). Stress, coping and burnout in nursing students. International Journal of Nursing Studies, 47(10), 1299-1309.

Gorham, J., \& Christophel, D. M. (1992). Students' perceptions of teacher behaviours as motivating and de-motivating factors in college class. Communication Quarterly, 40, 239-252.

Gorham, J., \& Millette, D. (1997). A comparative of analysis of teacher and student perceptions of sources of motivation and de-motivation in college classes. Communication Education, 46, 245-261.

Grossman, P., \& Stodolsky, S. (1995). Content as context: The role of school subjects in secondary school teaching. Educational Researcher, 24(8), 5-23.

Harackiewicz, J. M., Barron, K. E., Tauer, J. M., \& Elliot, A. J. (2002). Predicting success in college: A longitudinal study of achievement goals and ability measures as predictors of interest and performance from freshman year through graduation. Journal of Educational Psychology, 94, 562-575.

Hardré, P. L., \& Sullivan, D. W. (2007). Student differences and environment perception: How they contribute to student motivation in rural high schools. Learning and Individual Differences, 18, 471-485. 
Hasegawa, A. (2004). Student demotivation in the foreign language classroom. Language Studies, 107, 136-119. Hidi, S. (1990). Interest and its contribution as a mental resource for learning. Review of Educational Research, 60(4), 549-571.

Hidi, S., \& Renninger, K. A. (2006). The four-phase model of interest development. Educational Psychologist, 41(2), 111-127.

Huang, C. (2011). Achievement goals and achievement emotions: A meta-analysis. Education Psychology Review, 23, 359-388.

Hulleman, C. S., Schrager, S. M., Bodmann, S. M., \& Harackiewicz, J. M. (2010). A meta-analytic review of achievement goal measures: Different labels for the same constructs or different constructs with similar labels? Psychological Bulletin, 136, 422-449.

Ikeno, O. (2002). Motivating and demotivating factors in foreign language learning: A preliminary investigation. Journal of English Education Research, 2, 1-19.

Jackson, J. W. (2002). Enhancing self-efficacy and learning performance. The Journal of Experimental Education, 70, $243-55$.

Jahedizadeh, S., Allahdadi, S., \& Ghanizadeh, A. (2015). Probing the role of demotivation in avoidance goal orientation among EFL learners at private language institutes. International Journal of Research Studies in Psychology, 5(2), 3-14.

Jahedizadeh, S., \& Ghanizadeh, A. (2015). Demotivation and foreign language achievement: educational level and gender differences among Iranian EFL learners. International Journal of Foreign Language Teaching in the Islamic World, 3(6), 5-9.

Jahedizadeh, S., Ghanizadeh, A., \& Ghapanchi, Z. (2015). A Cross-contextual analysis of EFL students' burnout with respect to their gender and educational level. International Journal of English and Education, 4(3), 10-22.

Jahedizadeh, S., Ghonsooly, B., Ghanizadeh, A., \& Akbari, O. (2015). A cross-contextual analysis of EFL learners' perceptions of classroom activities. Journal of Applied Linguistics and Language Research, 2(4), 322-336.

Kharrazi, A., \& Kareshki, H. (2010). Environmental perceptions, motivational beliefs and self-regulating learning by Iranian high school students. Procedia Social andBehavioral Sciences, 5, 2160-2164

Kojima, S. (2004). English learning demotivation in Japanese EFL students: Research in demotivational patterns from the qualitative research results of three different types of high schools. Unpublished master thesis. Hyogo: Kwansei Gakuin University.

Kuittinen, M., \& Meriläinen, M. (2014). The effect of study-related burnout on student perceptions. Journal of International Education in Business, 4(1). doi: 10.1108/18363261111170586

Kumar, S., \& Jagacinski, C. M. (2006). Imposters have goals too: The imposter phenomenon and its relationship to achievement goal theory. Personality and Individual Differences, 40, 147-157.

Lee, J., Yin, H., \& Zhang, Z. (2009). Exploring the influence of the classroom environment on students' motivation and self-regulated learning in Hong Kong. The Asia-PacificEducation Researcher, 18(2), 219-232.

Leondari, A., \& Gonida, E. N. (2008). Adolescents' possible selves, achievement goal orientations, and academic achievement. Hellenic Journal of Psychology, 5(2), 179-198.

Linden, D. V. D., Keijsers, P. J., Eling, P., \& Schaijk, R. V. (2005). Work stress and attentional difficulties: An initial study on burnout and cognitive failures. Work and Stress, 19(1), 23-36.

Lizzio, A., Wilson, K., \& Simons, R. (2002). University students' perceptions of the learning environment and academic outcomes: Implications for theory and practice. Studies in Higher Education, 27(1), 27-52.

Maslach, C. (1976). Burned-out. Human Behavior, 9(5), 16-22.

Maslach, C., \& Jackson, S. (1986). The Maslach Burnout Inventory. Palo Alto. Calif: Consulting Psychologists Press.

Mattern, J. B. (2005). Why 'soft power' isn't so soft: Representational force and the sociolinguistic construction of attraction in world politics. Journal of International Studies, 33(3), 583-612.

McGregor, H. A., \& Elliot, A. J. (2002). Achievement goals as predictors of achievement-relevant processes prior to task engagement. Journal of Educational Psychology, 94, 381-395.

Middleton, M. J., \& Midgley, C. (1997). Avoiding the demonstration of lack of ability: An underexplored aspect of goal theory. Journal of Educational Psychology, 89, 710-718.

Midgley, C., Kaplan, A., Middleton, M., Maehr, M. L., Urdan, T., Anderman, L. H., Anderman, E., \& Roeser, R. (1998). The development and validation of scales assessing students' achievement goal orientations. Contemporary Educational Psychology, 23(2), 113-31.

Molavi, A., \& Biria, R. (2013). EFL learning among motivated and de-motivated Iranian seminary. Latin American Journal of Content and Language Integrated Learning, 6(1), 55-66.

Mousavi, F., \& Ghafelehbashi, M. (2015). Academic burnout in students: The predictive role of perfectionism and goal orientation. Journal of Studies in Educational Psychology, 12(21), 20-30.

Mucherah, W., \& Frazier, D. (2013). How deep is skin deep? The effects of skin color and self-Esteem on estimations of body image among women of African decent. Journal of Applied Social Psychology, 43(6), 1177-1184.

Nowell, C. (2007). The impact of relative grade expectations on student evaluation of teaching. International Review of Economics Education, 6(2), 42-56.

Oxford, R. L. (1998). The unravelling tapestry: Teacher and course characteristics associated with demotivation in the language classroom. Demotivation in Foreign Language Learning. Seattle: Paper presented at the TESOL '98 Congress.

Ozkal, K., Tekkaya, C., Cakiroglu, J., \& Sungur, S. (2008). A conceptual model of relationships among constructivist learning environment perceptions, epistemological beliefs, and learning approaches. Learning and Individual Differences, 19, 71-79.

Pajares, F. (2003). Self-efficacy beliefs, motivation, and achievement in writing: A review of the literature. Reading and Writing Quarterly, 19, 139-158.

Pajares, F., \& Cheong, Y. F. (2003). Achievement goal orientations in writing: A developmental perspective. International Journal of Educational Research, 39, 437-455.

Pekrun, R., Elliot, A. J., \& Maier, M. (2009). Achievement goals and achievement emotions: Testing a model of their joint relations with academic performance. Journal of Educational Psychology, 101(1), 115-135.

Pines, A., \& Kafry, D. (1978). Occupational tedium in the social services. Social Work, 23, 499-507.

Pintrich, P. R., \& DeGroot, E. V. (1990). Motivational and self-regulated learning components of classroom academic performance. Journal of Education Psychology, 82, 33-40. 
Pottage, D., \& Huxley, P. (1996). Stress and mental health social work: A developmental perspective. International Journal of Social Psychiatry, 42(2), 124-131.

Rezaee, M., \& Kareshki, K. (2012). A cross-comparison of achievement goal-orientations of Iranian and Afghani students. Paper presented at the 6th conference of university students' mental health. Iran: Gilan.

Rudnai, Z. (1996). Demotivation in learning English among secondary school students in Budapest (Unpublished master thesis). Budapest: Eo"tvo"s Lora'nd University.

Reichl, C., Wach, F.-S., Spinath, F. M., Brünken, R., \& Karbach, J. (2014). Burnout risk among first-year teacher students: The roles of personality and motivation. Journal of Vocational Behavior, 85, 85-92.

Rostami, Z., Abedi, M., \& Schaufeli, W. B. (2012). Dose interest predicts academic burnout? Interdisciplinary Journal of Contemporary Research in Business, 3(9), 877-885.

Sakai, H., \& Kikuchi, K. (2009). An analysis of de-motivators in the EFL classroom. System, 37, 57-69.

Schaufeli, W. B., Martinez, I., Pinto, A. M., Salanova, M., \& Bakker, A. B. (2002). Burnout and engagement in university students: A cross-national study. Journal of Cross-Cultural Psychology, 33(5), 464-481.

Shan, D. L., \& Jiang, G. F. (2012). Goal orientation and burnout: The mediating effects of academic self-efficacy among junior high school students. Psychological Science, 35(6), 1393-1397.

Schreiber, J. B., Amaury, N., Stage, F. K., Barlow, E. A., \& King, J. 2006. Reporting structural equation modeling and confirmatory factor analysis results: A Review. Journal of Educational Research, 99(6), 323-337.

Shen, B., Chen, A., \& Guan, J. (2007). Using achievement goals and interest to predict learning in physical education. Journal of Experimental Education, 75, 89-108.

Sideridis, G. D. (2005a). Goal orientation, academic achievement, and depression: Evidence in favor of a revised goal theory framework. Journal of Educational Psychology, 97, 366-375.

Skaalvik, E. (1997). Self-enhancing and self-defeating ego orientations: Relations with task and avoidance orientation, achievement, self-perceptions and anxiety. Journal of Educational Psychology, 89, 71-81.

Tsuchiya, M. (2004a). Nihonjin daigakuseino eigogakushuuheno demotivation (Japanese university students' demotivation to study English). The Chugoku Academic Society of English Language Education Kenkyukiyo, 34, 57-66.

Tsuchiya, M. (2004b). Factors in demotivation concerning learning English: A preliminary study of Japanese university students. The Kyushu Academic Society of English Language Education, 32, $39-46$.

Tsuchiya, M. (2006a). Factors in demotivation of lower proficiency English learners at college. The Kyushu Academic Society of English Language Education, 34, 87-96.

Tsuchiya, M. (2006b). Profiling of lower achievement English learners at college in terms of demotivating factors. Annual Review of English Language Education in Japan, 17, 171-180.

Ushioda, E. (1998). Effective motivational thinking: A cognitive theoretical approach to the study of language learning motivation. In E. A. Soler \& V. C. Espurz (Eds.), Current issues in English language methodology (pp. 77-89). Spain: Universita Jaume I.

Wachholtz, A., \& Rogoff, M. (2013). The relationship between spirituality and burnout among medical students. Journal of Contemporary Medical Education, 1(2), 83-91.

Yildirim, Z. (2004). Effect of technology competencies and online readiness on preservice teachers' use of online learning management system. Middle East: Paper presented at the European Conference on Educational Research, University College Dublin.

Young, A. J. (1997). I think, therefore I'm motivated: the relations among cognitive strategy use, motivational orientation and classroom perceptions over time. Learning and Individual Differences, 9(3), 249-283.

Zafarmand, A., Ghanizadeh, A., \& Akbari, O. (2014). A structural equation modeling of EFL learners' goal orientation, metacognitive awareness, and self-efficacy. Advances in Language and Literary Studies, 5(6), 112-124.

Zahed, A., Pourbahram, R., \& Rahmani, S. (2014). The relationship of perfectionism, goal achievement orientation and academic performance to academic burnout. Quarterly Journal of New Approach in Educational Administration, 5(2), 109-123.

Zhang, Q. (2007). Teacher misbehaviors as learning demotivators in college classrooms: A cross-cultural investigation in China, Germany, Japan, and the United States. Communication Education, 56, 209-227.

\section{Submit your manuscript to a SpringerOpen ${ }^{\circ}$ journal and benefit from:}

- Convenient online submission

- Rigorous peer review

- Immediate publication on acceptance

- Open access: articles freely available online

- High visibility within the field

Retaining the copyright to your article

Submit your next manuscript at $\gg$ springeropen.com 